EPiC Series in Engineering
Volume 3, 2018, Pages 1004-1012
HIC 2018. 13th International
Conference on Hydroinformatics

\title{
Optimal operation of flood storage areas in Huai River using coupled HEC-RAS river model and NSGAII global optimization algorithm
}

\author{
Andreja Jonoski ${ }^{1}$, Ioana Popescu ${ }^{1}$, Sun Zhe ${ }^{2}$ \\ ${ }^{1}$ IHE-Delft Institute for water education, Westvest 7, 2611 AX, Delft, the Netherlands \\ ${ }^{2}$ POWERCHINA Beijing Corp. LTD., 1, West Street, Dingfuzhuang, Chaoyang District, 100024 \\ Beijing, China \\ a.jonoski@un-ihe.org, i.popescu@un-ihe.org, sunzhecj@163.com
}

\begin{abstract}
In this work we present an application of coupled HEC RAS river model with NSGAII multi-objective optimization algorithm, for optimal operations of flood protection storage areas in the downstream part of Huai River in China. During flood, these storage areas are used for decreasing the flood water level downstream in order to protect the important, densely populated city of Bengbu. However, the same storage areas have also been used by local population, as both residential and agricultural zones, with high damage potential in case of flooding. The application investigates optimal operations of opening and closing the gates that connect the storage areas to the main river, which minimize the damage in the storage areas without compromising the protection of Bengbu. Two objectives are formulated related to: 1) downstream risk of flooding in Bengbu, and 2) damages in the storage areas. Decision variables are stage differences between the river and a given storage area, used for controlling gates operations (opening and closing). The coupling is performed in MATLAB using recently available HEC RAS API, known as HEC-RAS Controller. Initial results, obtained using flood hydrograph from the summer of 2007, indicate possible optimal operations, with selective usage of the storage areas.
\end{abstract}

\section{Introduction}

Huai River basin is located in the eastern central part of China, between the two large basins of Yellow River and Yangtze River (Figure 1). It has an area of about $270,000 \mathrm{~km}^{2}$ and average annual precipitation of about $880 \mathrm{~mm}$. However, this precipitation has highly uneven distribution in both space and time. The southern part of the basin has average precipitation of 1,400-1,600 mm, and most of the annual precipitation (50-80\%) comes during the wet season from June to October. With these 
characteristics, the basin suffers from frequent flood and drought disasters. Recent major flood disasters have occurred in 1991, 2003 and 2007. In past few decades, with rapid socio-economic development, especially in the middle and lower part of the basin, flood risk has significantly increased. Comprehensive flood risk management plans have been developed to cope with this situation, comprising both structural and non-structural measures (Mingkai and Kai 2017). Structural measures include flood retention reservoirs in the upstream part of the basin, dikes and diversions, and flood protection storage areas. Non-structural measures include institutional and legislative arrangements (with the central role of Huai River Basin Commission), flood risk assessment and mapping, flood forecasting and warning systems, and decision support systems for flood control operations. The research work presented here is relevant for this last part, where we investigate optimal operations of flood storage areas in the middle section of Huai River, by coupling a river flood simulation model with a multi-objective optimization algorithm.

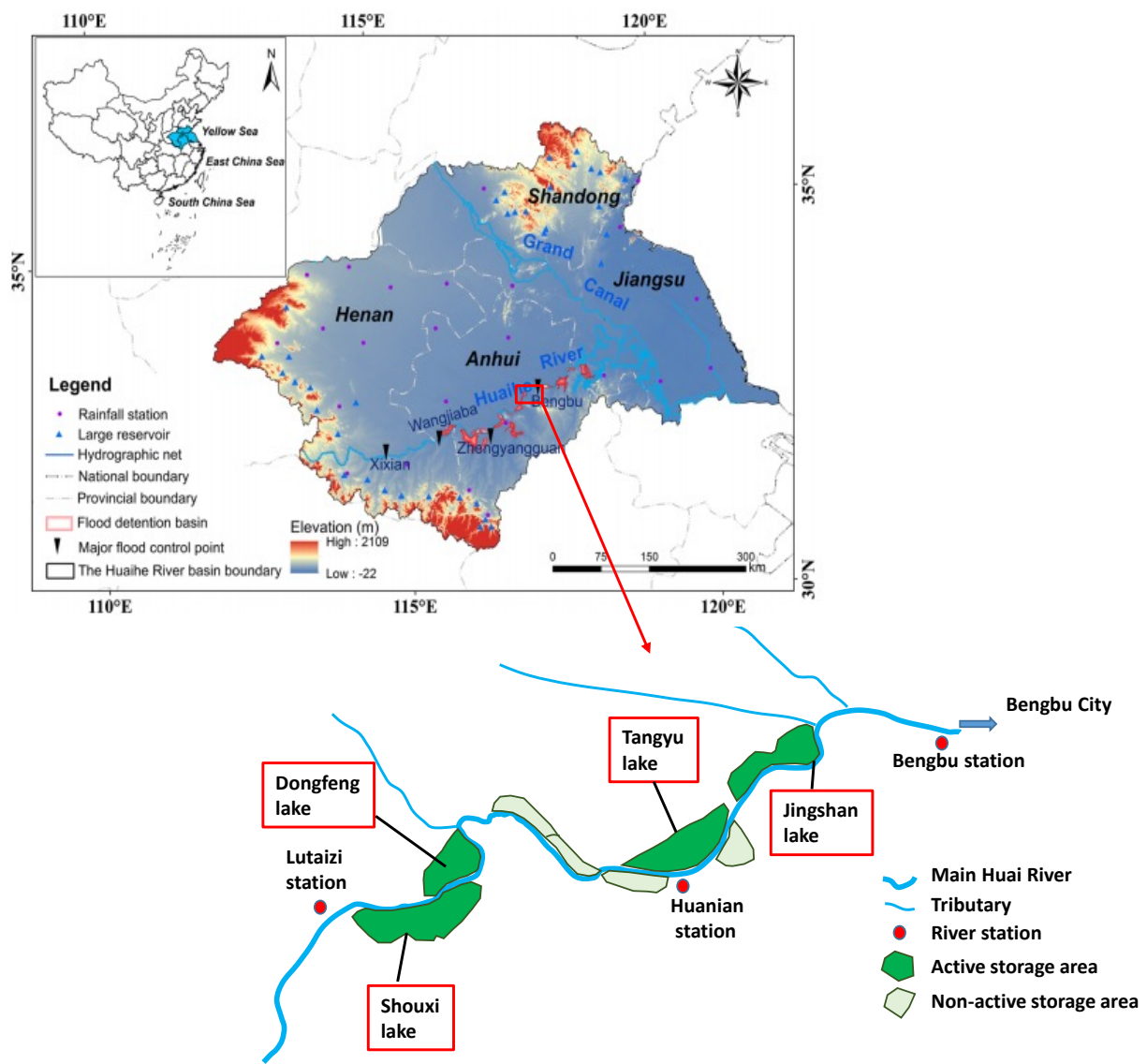

Figure 1. Huai River basin (adapted from (Wu, et al. 2015)) and scheme of the case study area

The considered stretch of the middle section of Huai River, covering about $110 \mathrm{~km}$, is located just upstream of Bengbu city, which has almost 3 million inhabitants and represents an important socioeconomic centre. Therefore, flood protection of Bengbu is of critical importance. In case of incoming flood from upstream, one measure for reducing the flood peak at Bengbu is to divert the flood waters into storage areas (or 'lakes'). In the past, eight such storage areas were used in this manner, but, after recent changes in the flood risk management plans, only four areas are now considered to be active 
for diverting incoming flood waters (Figure 1): Shouxi lake (capacity of $1,140 \times 10^{6} \mathrm{~m}^{3}$ ), Dongfeng lake $\left(259 \times 10^{6} \mathrm{~m}^{3}\right)$ Tangyu lake $\left(380 \times 10^{6} \mathrm{~m}^{3}\right)$ and Jingshan lake $\left(534 \times 10^{6} \mathrm{~m}^{3}\right)$. When not used for flood protection these same storage areas are used for agricultural activities associated with development of residential areas. Consequently, any usage of these flood storage areas during flood brings economic damage and even threats to loss of life. The problem addressed here is therefore focusing on developing optimal usage of these storage areas that minimizes their flood damages, while still ensuring the flood protection of Bengbu city. This leads to a formulation of an optimization problem with two conflicting objectives, as presented in the next sections.

\section{Literature review}

Multi-objective optimization of water systems by coupling of simulation models with different optimization algorithms has been widely researched during the last couple of decades. Example applications are numerous and diverse, regarding both application areas and types of algorithms used, although in most cases some variant of evolutionary algorithms has been used. Based on these experiences, a number of overview articles have recently published, presenting state of the art and current challenges, for example, (Reed, et al. 2013) and (Maier, et al. 2014). In flood-related studies, most of existing research in this area has been focused on optimization of operations of multi-purpose reservoirs, where flood protection is one of the reservoir operation objective. Similarly to the other application areas, the focus has been mostly on increasing the efficiency and dealing with uncertainties when using model-based optimisation (Salazar, et al. 2017). Application of the same methodology for optimal usage of flood storage areas, however, has been hardly addressed. Simulation-based analysis of flood storage area usage has been carried out (Förster, Chatterjee and Bronstert 2008), as well as optimization approaches for siting flood retention wetland areas (Zhang and Song 2014), but combined approaches for designing optimal operations of multiple flood storage areas have not been reported. The present article addresses this problem using coupled river simulation model and an evolutionary multi-objective optimization algorithm.

\section{Methodology}

The methodology includes development and calibration of a HEC-RAS river flood model in 1D for the study area, in which the storage areas are modelled as conceptual reservoirs. The model is then coupled with the well-known NSGAII multi-objective optimization algorithm (Deb, et al. 2002) in MATLAB, using the recently available HEC-RAS Controller API (Leon and Goodell 2016). Rather than considering actual time periods and corresponding releases into the storage areas as decision variables, which is common in reservoir operation studies, this optimization approach uses stage (water level) differences between the river and the storage areas as control variables. In HEC-RAS these can be set up to control the opening or closing of the inlet and outlet gates from the river to the storage areas and vice versa. In fact, these stage differences are treated as parameters to be optimized, which is an approach that is sometimes called optimization of myopic policies (Powell 2010).

The setup of the inlet and outlet gates is presented in Figure 2. All storage areas have an inlet and an outlet gate, except Dongfeng lake that has only an inlet gate. For the outlet gates, stage differences are fixed at $0.1 \mathrm{~m}$ for opening and $0 \mathrm{~m}$ for closing, as their use is only after the passage of the flood peak. For the inlet gates, additional constraint is that the stage differences for closing need to be smaller than those for opening. This is ensured by multiplying them with the stage differences for opening with a factor between 0 and 1 , which also becomes a decision variable for each inlet gate. In 
this way there are eight decision variables $\mathbf{X}=\left(x_{1}, \ldots x_{8}\right)$, as depicted in Figure 2. Their bounds have been determined by preliminary experimentation.

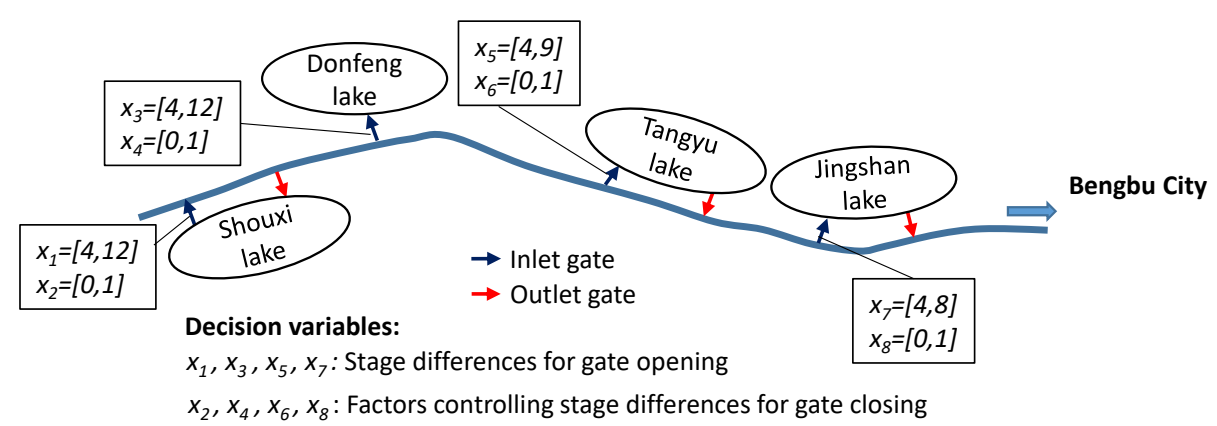

Figure 2 Conceptual representation of inlet and outlet gates and associated decision variables

Two objective functions have been formulated, first related to the downstream risk of flooding in Bengbu, and second related to weighted sum of total damages in the storage areas:

$\operatorname{MIN} F_{1}=w_{1}\left(y(\mathbf{X})-W_{l}\right)+w_{2}(d(\mathbf{X}))$

subject to :

$$
\begin{aligned}
& y(\mathbf{X})<S_{l} \\
& M I N F_{2}=\sum_{i=1}^{n} w_{i} g_{i}(\mathbf{X})
\end{aligned}
$$

, where: $\mathbf{X}$ - vector of decision variables; $F_{1}$ - downstream risk of flooding Bengbu comprised of two components: flood severity and flood duration; $y(\mathbf{X})$ - river water level at Bengbu; $W_{l}-$ flood warning level at Bengbu (20.3 $\mathrm{m}) ; d(\mathbf{X})$ - duration of river water level above flood warning level at Bengbu; $w_{1}$ and $w_{2}$ - weights for contribution of the two components to $F_{1}$ (assumed equal); $S_{l}-$ safeguard water level at Bengbu (22.57 m); $F_{2}$ - total weighted flood damage in all storage areas; $n$ number of storage areas; $w_{i}$ - weight for damage calculation in each storage area, proportional to number of inhabitants; $g_{i}(\mathbf{X})$ - total flood damage in a storage area comprising estimates of agricultural and residential damage. The constraint regarding not exceeding safeguard level at Bengbu $\left(S_{l}\right)$ is handled by introducing a penalty function to the first objective function.

From equation (1) it can be seen that the first objective function is in fact a weighted sum of two downstream risk factors for Bengbu city: the severity of the flood (how much is the water level above the warning level) and the duration of the flood (how many days is the river water level above the warning level). This formulation was chosen for allowing flexibility in further experimentation. In general, the downstream risk can also be formulated with a different objective function. The estimates of agricultural and residential damage, used to calculate the total damage in a storage area $\left(2^{\text {nd }}\right.$ objective function), depend on the water level in the storage area compared to the so-called 'Zhuangtai' level, above which all housing should be located (normally about $3 \mathrm{~m}$ above the bottom of the storage area). The estimates of damages for each storage area are:

- If maximum inundation level $>$ Zhuangtai level

residential : $P=p\left[s_{1}\left(I_{\max }-H\right)+s_{2} I_{\max }\right]$

agricultural : $C=a b d_{1} I_{\text {end }}$

- If maximum inundation level $<$ Zhuangtai level 
residential $: P=p s_{2} I_{\max }$

agricultural : $C=a b d_{2} I_{\text {end }}$

, where: $P$ - residential damage, $C$-agricultural damage, (and $g(\mathbf{X})=P+C$ ), $p$ - population in the storage area, $s_{1}$ - housing asset value (RMB), $s_{2}$ - equipment asset value (RMB), $I_{\max }-$ maximum inundation level (m), $H$ - height from bottom of storage area to Zhuangtai level $(\mathrm{m}), a$ - farming area (ha), $b$ - crop value per unit area (RMB), $I_{e n d}$ - final inundation level, $d_{1}-$ high damage rate, $d_{2}-$ low damage rate. The assumed values of these parameters are given in Table 1:

\begin{tabular}{|c|c|c|c|c|c|c|c|c|}
\hline $\begin{array}{l}\text { Storage } \\
\text { area }\end{array}$ & $\begin{array}{c}p \\
\text { (person) }\end{array}$ & $\begin{array}{r}{ }^{a} \\
(h a)^{2}\end{array}$ & (m) ${ }^{H}$ & $\begin{array}{c}S l \\
(R M B)\end{array}$ & $\begin{array}{c}s_{2} \\
(R M B)\end{array}$ & $\begin{array}{c}b \\
(R M B / h a)\end{array}$ & $d_{l}$ & $d_{2}$ \\
\hline Shouxi & 86,000 & 11,333 & 3 & 400 & 100 & 4,500 & 0.6 & 0.4 \\
\hline Donfeng & 19,800 & 3,733 & 3 & 400 & 100 & 4,500 & 0.6 & 0.4 \\
\hline Tangyu & 25,800 & 6,000 & 3 & 500 & 200 & 4,500 & 0.6 & 0.4 \\
\hline Jingshan & 11,700 & 5,733 & 3 & 500 & 200 & 4,500 & 0.6 & 0.4 \\
\hline
\end{tabular}

Table 1 Assumed data for calculating flood damage in storage areas

\section{Results and discussion}

The analysis used upstream flood hydrograph of the summer in 2007, with flood peak of about $7,850 \mathrm{~m} 3 / \mathrm{s}$ and duration of the flood hydrograph of about two months. The modelled maximum water level at Bengbu river station without usage of the storage areas was about $20.82 \mathrm{~m}$, with duration of about 10 days above the warning level $(20.3 \mathrm{~m})$. After several test runs, an optimization was performed with 5,000 function evaluations (HEC-RAS model runs), with population of 50 and 100 generations. This optimization run took about 20 hours on a standard laptop and produced the Pareto set of solutions as depicted in Figure 3 below. Two clusters of solutions were produced, depending on whether the largest storage area of Shouxi lake was used or not. The upper cluster represents high damage in the storage areas, when Shouxi lake is used, with reductions in downstream risk up to 20.5 $\mathrm{m}$ maximum water level and 3.2 days duration above warning level. The lower cluster represents solutions when Shouxi lake is not used, without much reduction in downstream risk, and lower flood damages. The two marked solutions in Figure 3 have very similar results for downstream risk (with $y(\mathbf{X})=2.2 \mathrm{dm}$ and $d(\mathbf{X})=3$ days), with large difference in damage, due to usage of the Shouxi lake.

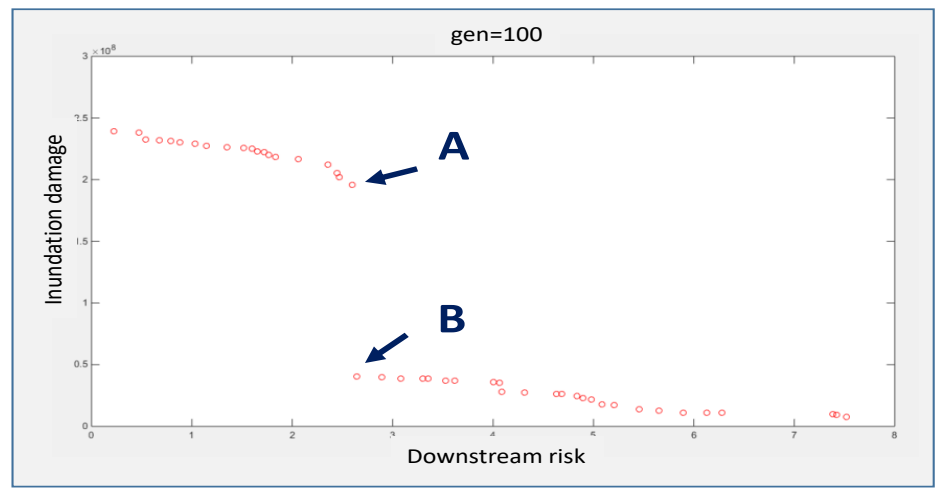

Figure 3 Pareto set of optimal solutions grouped in two clusters 
The results in terms of damage of the two indicated solutions (A and B) in Figure 3 are summarised in Table 2.

\begin{tabular}{lccccc}
\hline Solution & Total & Shouxi & Dongfeng & Tangyu & Jingshan \\
\hline A & $1.96 \times 10^{8}$ & $1.56 \times 10^{8}$ & $1.61 \times 10^{7}$ & $2.05 \times 10^{7}$ & $3.84 \times 10^{6}$ \\
B & $4.03 \times 10^{7}$ & 0 & $1.62 \times 10^{7}$ & $2.02 \times 10^{7}$ & $3.86 \times 10^{6}$ \\
\hline
\end{tabular}

Table 2 Flood damage results (weighted by population) for solutions A and B of Figure 3

These results clearly indicate that the differences between solutions A and B (and their neighbouring clusters) are only in utilising Shouxi lake.

This is also confirmed with the results in terms of obtained values for the decision variables, which for the same solutions A and B (indicated in Figure 3) are presented in Table 3. Note that the head differences for closing of the inlet gates $\left(x_{2}, x_{4}, x_{6}, x_{8}\right)$ are given with their actual values, while in the optimization they were calculated as a factor between 0 and 1 of the head differences for opening

\begin{tabular}{lcccccccc}
\hline Solution & $x_{1}$ & $x_{2}$ & $x_{3}$ & $x_{4}$ & $x_{5}$ & $x_{6}$ & $x_{7}$ & $x_{8}$ \\
\hline A & 11.1 & 4.3 & 8.6 & 3.1 & 6.6 & 0.4 & 4.8 & 0.5 \\
B & $/$ & $/$ & 8.8 & 3.1 & 6.6 & 0.5 & 4.8 & 0.5 \\
\hline
\end{tabular}

Table 3 Decision variables results (head differences in $\mathrm{m}$ ) for solutions A and B of Figure 3

the same gates.

For each of the obtained solutions, HEC-RAS results can be extracted for further analysis of the resulting usage of the storage areas and flood hydrograph modification in the min river. Figure 4, Figure 5 and Figure 6 present the operation of Dongfeng, Tangyu and Jungshan with solution B.

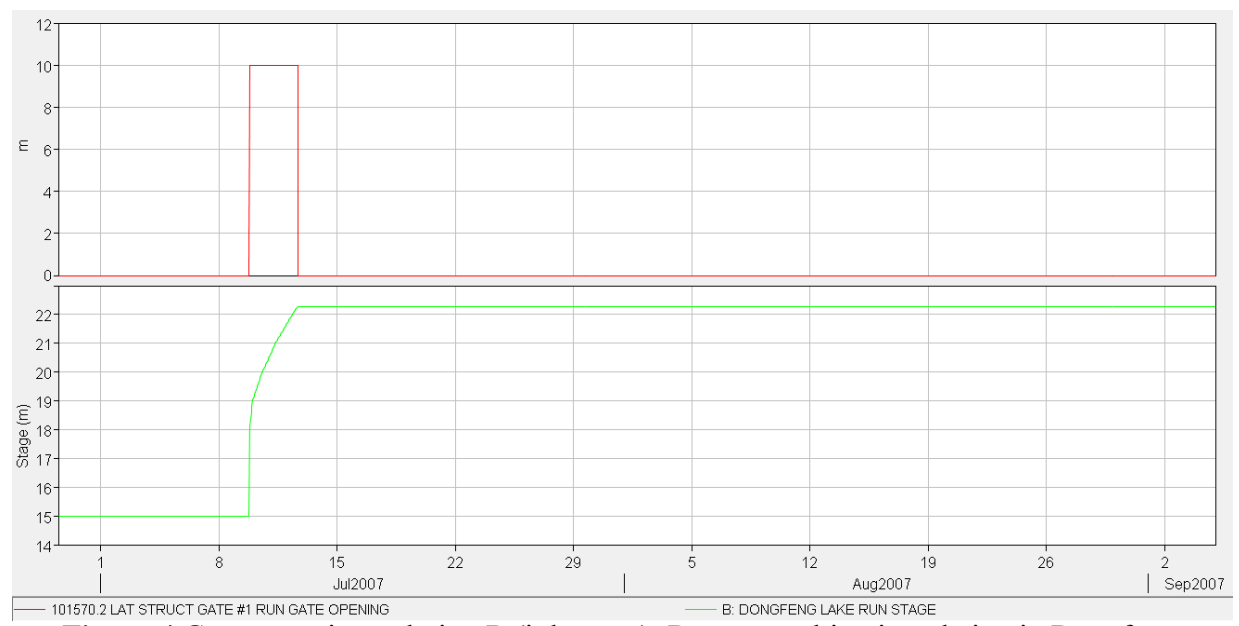

Figure 4 Gate operation-solution B (inlet gate); Down: resulting inundation in Dongfeng 


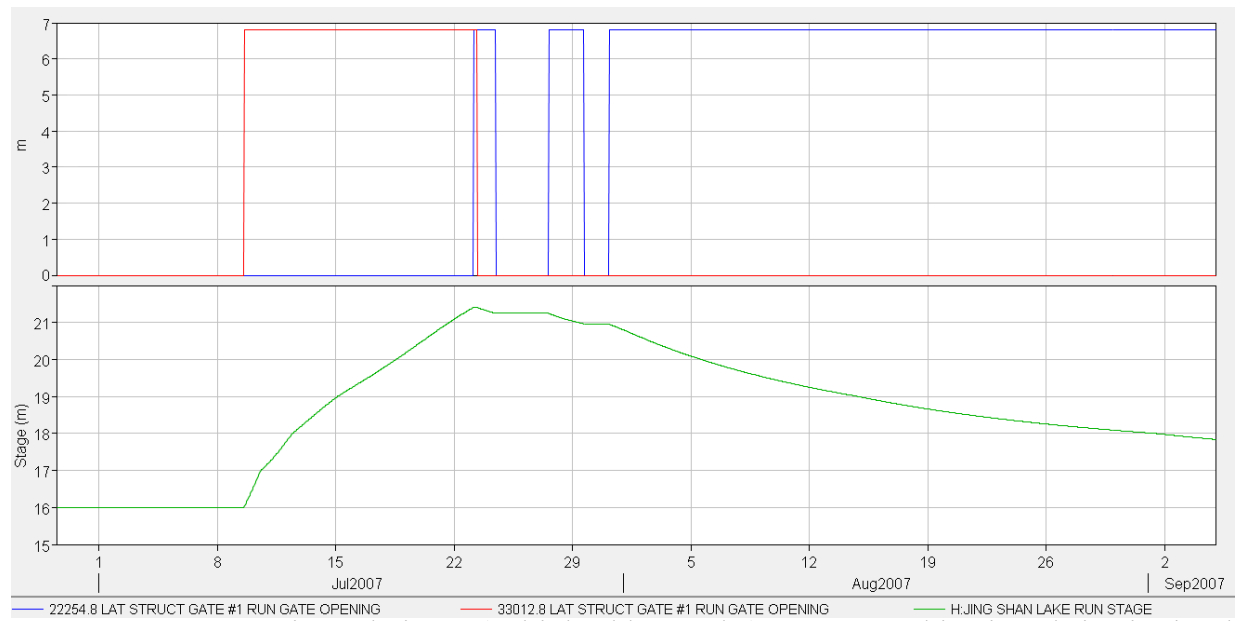

Figure 6 Up: Gate operation-solution B (red-inlet, blue-outlet); Down: resulting inundation in Jingshan

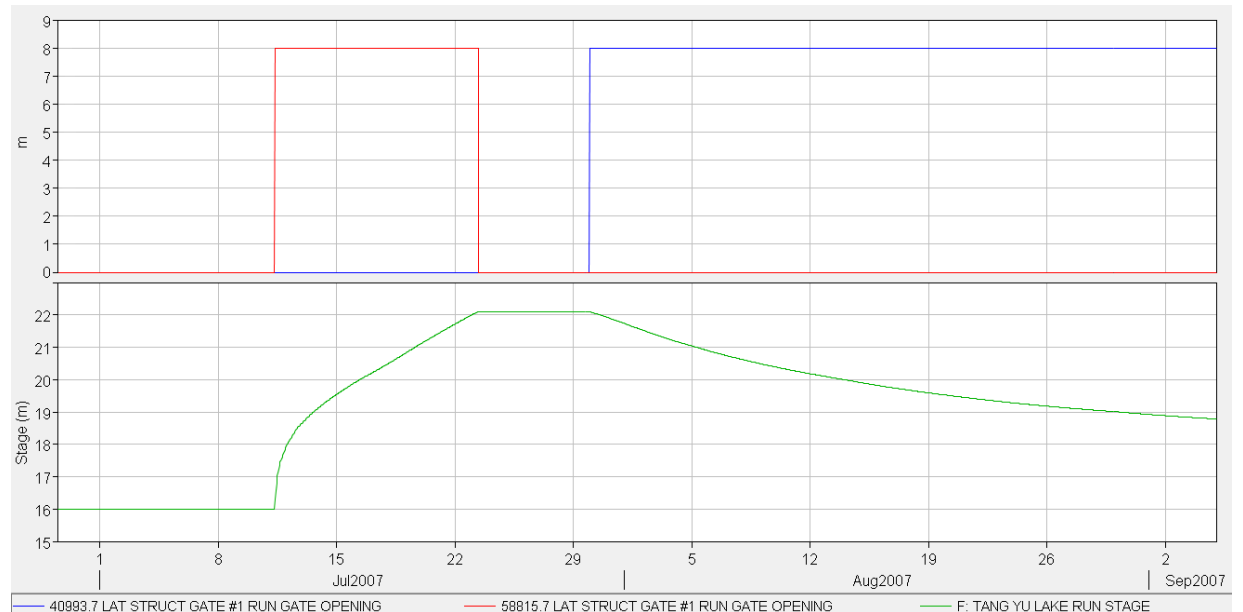

Figure 5 Gate operation-solution B (red - inlet, blue - outlet); Down: resulting inundation in Tangyu

Sometimes the gates can be opened and closed several times in sequence, as can be seen in Figure 6 for the outlet gate of Jingshan. 
The resulting modification of the flood hydrograph with the same solution (B) at the downstream location of Bengbu city is presented in Figure 7.

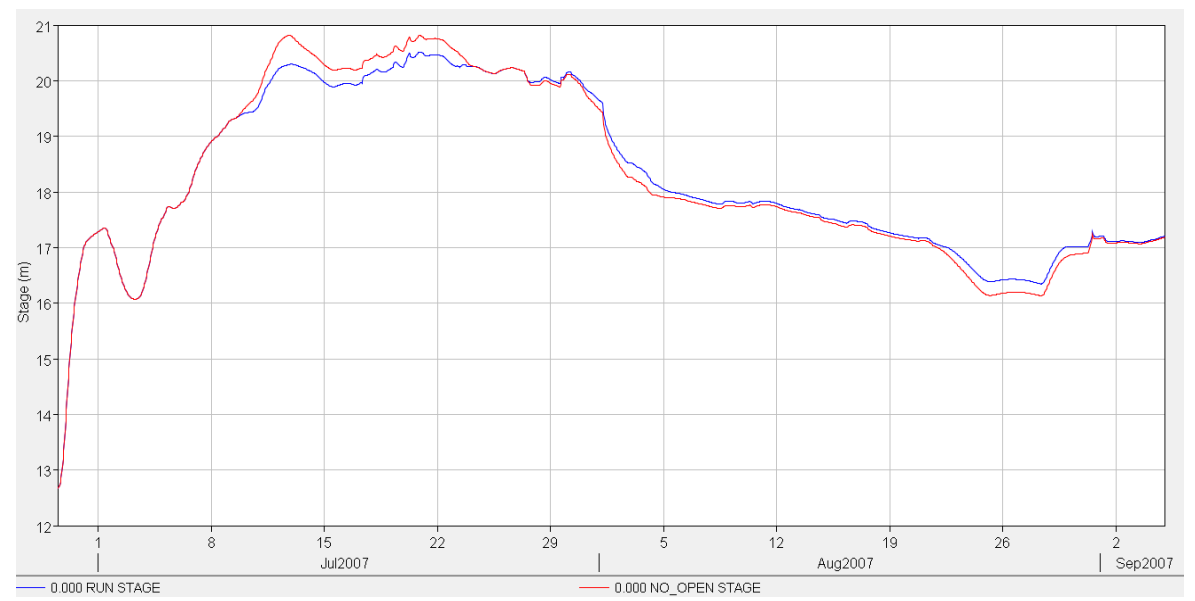

Figure 7 Hydrograph modification at Bengbu: red - original; blue - with solution B

Clearly, with solution B the hydrograph is reduced around the peak, even if later on the water level is somewhat higher than the original situation, as water is released back into the river from the storage areas.

Similar results can be extracted for any solution belonging to the Pareto set presented in Figure 3 . Finally it needs to be noted that there are also two extreme solutions in Figure 3, one with highest flood damage (second objective function value of about $2.5 \times 10^{8}$ ) and minimal downstream risk, and another with minimal damage and very high downstream risk (first objective function value of about 7.5), which practically does not modify the original flood hydrograph at Bengbu at all.

\section{Conclusions and recommendations}

This work demonstrated optimization of flood storage areas operation, in which HEC-RAS model was coupled with NSGAII algorithm. The coupling was realised in MATLAB, by making use of the recently developed HEC-RAS Controller API, which enables controlling the HEC-RAS model input and setup, and extraction of relevant model results. The model-based optimization resulted in a set of optimal operational policies for the four considered storage areas, grouped in two separate clusters, depending on usage of the largest storage area in the case study - Shouxi lake.

This work can be extended in several different directions: Firstly, a more controlled usage of Shouxi lake may be sought, by selecting different bounds for the decision variables, that may be linked with actual damage calculations in the four storage areas. Some modifications of the formulations of the objective functions may also be introduced, both for better calculation of actual flood damage in the storage areas and for better utilisation of Shouxi lake. Further research can also investigate usage of different optimisation algorithms. A significant extension of this research would be in including 2D representation of flooding in storage areas, for more detailed damage estimation, which may also lead to improved utilisation of Shouxi lake. Finally, a sensitivity analysis of the obtained solutions to the shape of the upstream flood-causing hydrograph is required for obtaining more reliable operational policies in different conditions. 


\section{References}

Deb, K., A. Pratap, S. Argawal, and T. Meyarivan. 2002. "A fast elitist multi-objective genetic algorithm NSGA-II." IEEE Trans Evol Comput 6: 182-197.

Förster, S., C. Chatterjee, and A. Bronstert. 2008. "Hydrodynamic simulation of the operational management of a proposed flood emergency storage area at the Middle Elbe River." River Res. Applic. 24: 900-913.

Leon, A.S., and C. Goodell. 2016. "Controlling HEC-RAS using MATLAB." Environmental Modelling \& Software 84: 1364-8152.

Maier, H.R., Z. Kapelan, J. Kasprzyk, J. Kollat, L.S. Mattot, M.C. Cunha, G.C. Dandy, et al. 2014. "Evolutionary algorithms and other metaheuristics in water resources: Current status, research challenges and future directions." Environmental Modelling \& Software 62: 271299.

Mingkai, Q., and W. Kai. 2017. "Flood management in China: The Huaihe River Basin as a case Study." By Dr. Ted Hromadka (Ed), 129-152. InTech.

Powell, W.B. 2010. "Approximate Dynamic Programming: 1 Modeling." In Wiley Encyclopedia of Operational Research and Management Science, by J. Cochran (Ed.). John Wiley \& Sons.

Reed, P.M., D. Hadka, J.D. Herman, J.R. Kasprzyk, and J.B. Kollat. 2013. "Evolutionary multiobjective optimization in water resources: The past, present and future." Advances in Water Resources 51: 438-456.

Salazar, J.Z., P.M. Reed, J.D. Quinn, M. Giuliani, and A. Castelleti. 2017. "Balancing exploration, uncertainty and computational demands in many objective reservoir optimization." Advances in Water Resources 109: 196-210.

Wu, Y., P. Zhong, Y. Zhang, B. Xu, B. Ma, and K. Yan. 2015. "Integrated flood risk management and zonation method. A case study in Huaihe River Basin, China." Natural Hazards 78: 635-651.

Zhang, X., and Y. Song. 2014. "Optimization of wetland restoration siting and zoning in flood retention areas of river basins in China: A case study in Mengwa, Huaihe River Basin." Journal of Hydrology 519: 80-93. 